\title{
UNA PROPUESTA DE ENSEÑANZA INNOVADORA EN LA FORMACIÓN DE PROFESORES DE NIVEL PRIMARIO: LA TEMPORALIDAD EN LA ENSEÑANZA DE LAS CIENCIAS SOCIALES
}

\author{
Lucrecia Milagros Alvarez* \\ Universidad Nacional del Litoral, Argentina \\ lucreciamilagros@gmail.com
}

Recibido: 16/08/2019 Aceptado: 5/12/2019

\section{Resumen}

Este artículo se enmarca en el Proyecto CAI+D 2016: Prácticas de enseñanza innovadoras en Geografía e Historia que promueven el pensamiento crítico (Universidad Nacional de Litoral). En el marco de la investigación, los miembros del equipo nos encontramos identificando prácticas innovadoras realizadas en los distintos niveles y modalidades del sistema educativo.

En este caso, presentamos una experiencia que consideramos novedosa, llevada a cabo en el marco del taller de Problemática de las Ciencias Sociales, correspondiente al primer año de los Profesorados de Nivel Primario de la provincia de Santa Fe (Argentina).

En este escrito se analizan dos trabajos prácticos realizados por los futuros docentes:

El Trabajo práctico № 1, que consistió en la elaboración de una planificación para la enseñanza de las Ciencias Sociales en el nivel primario, sobre los temas enseñados durante el taller.

Y el Trabajo práctico № 2, en el que debían incorporar en la planificación antes mencionada, el concepto estructurante de tiempo histórico, a partir de la elaboración de una actividad y el diseño de los recursos/materiales para sus futuros estudiantes.

Consideramos, que la divulgación de estas experiencias realizadas en el nivel superior, promueven la formación profesional de los docentes actuales y futuros, y la reflexión sobre la propia práctica de enseñanza de la profesora dictante del taller.

Palabras clave: Innovación - Tiempo histórico - Enseñanza - Ciencias sociales - Nivel primario.

\section{Abstract}

This article is part of the CAI+D 2016 Project: Innovative teaching practices in Geography and History that promote critical thinking (National University of Litoral). Within the framework of the research, the team members are identifying innovative practices carried out at the different levels and modalities of the education system.

In this case, we present an experience that we consider novel, carried out within the framework of the Social Science Problems workshop, corresponding to the first year of the Primary Level Teachers of the province of Santa Fe (Argentina). This paper analyzes two practical works carried out by future teachers:

Practical Work No. 1, which consisted in the elaboration of a planning for the teaching of Social Sciences at the primary level, on the subjects taught during the workshop, and Practical Work № 2, in which they had to incorporate in the aforementioned planning, the structuring concept of historical time, from the elaboration of an activity and the design of the resources / materials for their future students.

\footnotetext{
* Magíster en Didácticas Específicas (UNL). Diploma Superior en Enseñanza de las Ciencias Sociales y de la Historia (FLACSO). Profesora de Historia (UNL). Integrante del CAI+D 2016 "Prácticas de enseñanza innovadoras en Geografia e Historia que promueven el pensamiento crítico" (UNL); director: Oscar Lossio, co-directora Mariela Coudannes. Miembro activo de APEHUN (Asociación de Profesores/as de Enseñanza de la Historia de Universidades Nacionales). Integrante del Centro de Estudios Sociales Interdisciplinarios del Litoral (CESIL).
} 
We believe that the dissemination of these experiences carried out at the higher level, promote the professional training of current and future teachers, and reflection on the teaching practice of the workshop teacher.

Keywords: Innovation - Historical time - Teaching - Social sciences - Primary level.

\section{Introducción}

Este artículo se enmarca en el Proyecto CAI+D 2016: "Prácticas de enseñanza innovadoras en Geografía e Historia que promueven el pensamiento crítico ". La metodología empleada es cualitativa y se inscribe en la tradición interpretativa y crítica.

En esta instancia del proyecto de investigación, los profesores-investigadores, nos encontramos identificando prácticas innovadoras que promuevan el pensamiento crítico en los alumnos, en los distintos niveles del sistema educativo en los que trabajamos.

En este caso, presentamos una experiencia que consideramos novedosa, realizada en el marco del taller de Problemática de las Ciencias Sociales, correspondiente al primer año de los Profesorados de Nivel Primario de la provincia de Santa Fe (Argentina).

Se describen y analizan los trabajos prácticos realizados por los futuros docentes relacionados con:

A) la elaboración de una planificación para la enseñanza de las Ciencias Sociales en el nivel primario sobre los temas enseñados durante el taller ${ }^{2}$, en la que debían incluir: el tema y el problema a enseñar, los objetivos, la fundamentación disciplinar y didáctica, la descripción metodológica de la propuesta y la secuenciación de clases, las actividades/materiales para sus futuros estudiantes y las posibles formas de evaluación (Trabajo práctico № 1, grupal escrito).

B) la incorporación en la planificación antes mencionada, del concepto estructurante de tiempo histórico ${ }^{3}$, a partir de la elaboración de una actividad y el diseño de los recursos/materiales para sus estudiantes (Trabajo práctico № 2, individual escrito).

Consideramos que la divulgación de estas experiencias realizadas en el nivel superior, promueven la formación profesional de los docentes en formación y en ejercicio, alentando la relación que desearíamos exista más profundamente, entre la enseñanza de las Ciencias Sociales, la investigación en Didáctica de las Ciencias Sociales y la formación docente (Imbernón, 2002; Latorre 2003).

\section{El taller de Problemática de las Ciencias Sociales en el diseño curricular, en el contexto institucional y en el espacio del aula}

En el diseño curricular jurisdiccional de la provincia de Santa Fe, que corresponde al Profesorado de Educación Primaria (Res. 528/09), este taller es del campo de la formación específica y del sub-campo de aproximación a las problemáticas del conocimiento. Se dicta para los alumnos de primer año durante el segundo cuatrimestre del año académico.

El mismo, se propone iniciar a los estudiantes en los siguientes ejes ${ }^{4}$ :

-Especificidad de las miradas y producciones de las diversas disciplinas del campo de las Ciencias Sociales;

-La Historia y la Geografía como disciplinas científicas y escolares;

-Conceptos estructurantes de las Ciencias Sociales: tiempo, espacio, rupturas y permanencias, estructura, proceso, causalidad y multicausalidad, actores y relaciones sociales;

-Nuevos enfoques científicos en la Historia y la Geografía a partir de la segunda mitad del siglo XX: historia social y de la vida cotidiana; geografía de la percepción y crítica. Aportes conceptuales a la enseñanza;

-Metodologías: estudios de caso, los trabajos por proyectos, la resolución de problemas, la investigaciónacción.

Junto con el currículum prescripto, al interior de la institución formadora en dónde se realizó esta experiencia, existía un consenso entre los docentes dictantes del taller en las cinco divisiones de primer año, en enseñar contenidos históricos desde el peronismo hasta la actualidad (1943/1946 - presente), con el objetivo de que el taller, fuera una continuidad de las temáticas/problemáticas abordadas en el primer cuatrimestre del año académico, en la materia Historia argentina y latinoamericana en la que se incluyen temáticas que temporalmente se enmarcan entre 1850 - 1955.

\footnotetext{
${ }^{1}$ Aprobado por la Universidad Nacional del Litoral. (Res. C. S. 048/17). Director: Oscar Lossio. Co-directora: Mariela Coudannes Aguirre.

${ }^{2}$ La planificación de los futuros docentes de nivel primario, no tuvo por objetivo en esta primera experiencia, abordar contenidos específicos de la enseñanza primaria, sino llevarse a cabo como un ejercicio de simulación, en el que los estudiantes de nivel superior planificaron sobre los contenidos/problemáticas que ellos mismos debían aprender en el marco del Taller.

${ }^{3}$ En este artículo los conceptos de tiempo histórico y temporalidad se utilizan de manera intercambiable.

${ }^{4}$ Según el diseño curricular provincial mencionado, estos ejes se profundizarán a lo largo del cursado de la carrera en otras materias como por ejemplo Ciencias Sociales y su didáctica I y II.
} 
Como docente reemplazante de larga duración a cargo del taller, tomé la decisión metodológica de profundizar las sugerencias del diseño curricular con el objetivo de realizar una primera aproximación al campo de las ciencias sociales y sus problemáticas. Con este propósito, abordé los siguientes ejes con los futuros profesores:

*Las Ciencias Sociales y su enseñanza, reflexión sobre algunas problemáticas sociales actuales (Siede, 2010);

${ }^{*}$ El contexto sociohistórico de surgimiento de las Ciencias Sociales: la llustración, la Revolución Francesa, la Revolución industrial y el capitalismo (Canales, Estrada y Luna, 2006);

*Las diferentes ciencias sociales y su objeto de estudio: Sociología-Economía- Antropología- HistoriaGeografía- Derecho- Psicología (Xiqui, 2016),

*Investigaciones en Ciencias Sociales. Las Ciencias Sociales en la escuela:

a) análisis de propuestas de enseñanza para el nivel primario (Alvarez, Andelique y Coudannes, 2016; Jara y Funes (comp.) 2016; Siede, 2010);

b) El sentido común, la Historia y la Geografía como disciplina escolar (Romero, 2004);

${ }^{*}$ Conceptos estructurantes de las Ciencias Sociales: el tiempo histórico y las categorías temporales (Benejam, 1999; Pagés 1989; 1997a; Pagés y Santisteban 2010); el espacio geográfico y las categorías espaciales (Benejam, 2013; Zenobi, 2016);

*La enseñanza a partir del planteo de problemas sociales relevantes (Santisteban; González Monfort; Pagès y Oller, 2013).

Consideramos que esta experiencia áulica que presentamos, es innovadora porque definimos al concepto de innovación en el marco de la investigación en curso, como la incorporación de algo nuevo a una realidad existente, o el surgimiento de algo nuevo al interior de esa realidad, y su resultado (Lipsman, 2009). En este sentido, lo novedoso estuvo dado por:

1) la metodología utilizada en el transcurso de las clases que combinó: la explicación de la bibliografía obligatoria con la realización de trabajos grupales/individuales, escritos/orales que los futuros profesores fueron elaborando de manera continuada y progresiva, tomando como base el trabajo práctico № 1 ;

2) el diseño de una primera planificación para la enseñanza en el nivel primario en el que se desempeñarán los estudiantes del profesorado en el futuro, que implicó la fundamentación de la misma, junto con el diseño de actividades y materiales/recursos para sus estudiantes en una primera instancia en relación con el tema/problema elegido; y luego, incorporando en ellos explícitamente el tiempo histórico. Consideramos que la realización de estos trabajos les posibilitó pensarse como docentes desde el primer año de su trayecto formativo (Sanjurjo, 2005);

3) la introducción en el espacio del aula de nivel superior de problemáticas sociales y educativas históricas y actuales, que los futuros profesores eligieron para enseñar, con las cuáles se vieron implicados política y éticamente;

4) la selección de los temas/problemas a enseñar en el marco del taller en consonancia con el diseño curricular e incorporando a las Ciencias sociales como disciplinas científicas y enseñadas, fue novedosa porque se introdujo en la práctica de la enseñanza (Edelstein, 2007; Edelstein y Coria, 1999), un cambio metodológico, didáctico y disciplinar;

5) la diversidad de trabajos prácticos realizados diversos y el análisis que aquí presentamos implica también, una reflexión sobre la propia práctica de enseñanza por parte de la docente a cargo del taller.

\section{Innovación y temporalidad en la enseñanza de las Ciencias Sociales}

Para ampliar la conceptualización de lo que definimos como innovación, tomamos las palabras de Campilia (2017), que analiza la potencialidad de las experiencias innovadoras en el aula de nivel secundario, que consideramos también aplicable al nivel superior:

La búsqueda de estrategias alternativas para la enseñanza tiene la potencialidad de modificar tanto el modelo escolar como la organización institucional. Así, es deseable que, sobre la base de la propuesta pedagógica y de organización escolar, una nueva cartografía de la enseñanza pueda plasmarse progresivamente en cada escuela en función del contexto y que comiencen a instalarse nuevas formas de enseñanza (Campilia, 2017, p.14)

Por su parte, Jara y Boixader (2014) argumentan que deberían realizarse algunas de las siguientes actividades a fin de llevar a cabo prácticas de enseñanza y aprendizaje innovadoras: realizar actividades de investigación compartida con el alumnado, aprender a formular hipótesis, preguntas, problemas; invitar al alumnado a proponer preguntas e impulsar procesos metodológicos que tengan entre sus características principales el uso del diálogo, la conversación, la participación, el consenso (o el disenso) como debates o foros, entre otros. 
En relación al tiempo histórico, desde el marco teórico ${ }^{5}$ de la Didáctica de las Ciencias Sociales y la Historia, lo definimos como:

- $\quad$ concepto estructurante de la disciplina (Benejam, 1999)

- $\quad$ metaconcepto polisémico (Pagès 1989; Pagès y Santisteban, 1999, 2008 y 2011)

- $\quad$ metacategoría (Pagès 1997a; Pagès y Santisteban, 2011)

- $\quad$ construcción social (Pagès y Santisteban, 1999; Santisteban 2007; Pagès 2014)

- $\quad$ construcción cultural (Pagès 1997a)

Pagès (1989; 1997a), diseña una estructura conceptual para la enseñanza del tiempo histórico y las categorías temporales, dado que una de las tensiones que atraviesan la escolaridad obligatoria, es que la temporalidad individual y social se construye por fuera de la escuela y además, no es un contenido central en los currículum de Historia y de Ciencias Sociales.

En este sentido, para Santisteban (2014), las categorías temporales fundamentales a ser enseñadas en la escuela deberían ser el cambio y la continuidad, y la relación entre el pasado, el presente y el futuro.

Teniendo en cuenta las consideraciones precedentes, es fundamental que los futuros profesores de enseñanza primaria, durante su formación, diseñen propuestas de enseñanza en las que incluyan explícitamente el tratamiento de la temporalidad y elaboren materiales/recursos para tal fin.

\section{Los trabajos de los futuros profesores de nivel primario}

A continuación presentamos la tabla I que sintetiza los trabajos prácticos realizados por los estudiantes. En esta oportunidad, seleccionamos para el análisis del trabajo práctico № 1 el tema/problema elegido para enseñar en el nivel primario, junto con las actividades y los recursos/materiales preparados para sus futuros estudiantes.

En la Tabla II incluimos los aportes individuales del trabajo práctico № 2, las actividades y los recursos/materiales a partir de los cuáles incorporaron específicamente el tratamiento de la temporalidad.

Tabla I:

\begin{tabular}{|l|l|}
\hline \multicolumn{2}{|c|}{ Planificación para la enseñanza de las Ciencias Sociales en el nivel primario } \\
\hline \multicolumn{1}{|c|}{ Tema/problema TP № 1 (grupal) } & \multicolumn{1}{c|}{ Actividades y los recursos/materiales } \\
\hline $\begin{array}{l}\text { GRUPO 1 ¿a historia como ciencia social ¿Qué es la historia } \\
\text { como ciencia social? }\end{array}$ & $\begin{array}{l}\text { Clase 1: Buscar información sobre qué es la Historia como } \\
\text { ciencia social y sobre su objeto de estudio. } \\
\text { Máquina del tiempo, actividad de imaginación para pensar a } \\
\text { qué tiempo histórico viajarían los niños. } \\
\text { Traer para la próxima clase imágenes de la época a la que los } \\
\text { estudiantes eligieron viajar (búsqueda de las mismas en su } \\
\text { casa). } \\
\text { Clase 2: A partir de los aportes de los alumnos y de las } \\
\text { imágenes, se armará entre todos una línea de tiempo en el } \\
\text { pizarrón, en la que se incluyan las épocas seleccionadas por } \\
\text { los estudiantes ordenadas cronológicamente }\end{array}$ \\
\hline $\begin{array}{l}\text { GRUPO 2 } \\
\text { La historia como disciplina científica y sus fuentes. } \\
\text { Diversas fuentes que utiliza el historiador para } \\
\text { investigar la última dictadura militar en Argentina } \\
\text { (1976-1983): publicidades, música, moda, deportes } \\
7^{\circ} \text { grado }\end{array}$ & $\begin{array}{l}\text { Clase 1: Video de "Zamba en la Casa Rosada" como } \\
\text { introducción al tema de la última dictadura militar en nuestro } \\
\text { país. Debate. } \\
\text { Realización de una pequeña investigación a partir de fuentes } \\
\text { primarias y secundarias sobre: publicidades de la época; } \\
\text { deporte y dictadura; la moda y la censura; música. } \\
\text { Trabajo en el aula con preguntas guías elaboradas por el/la } \\
\text { docente, letras de canciones, imágenes, link de videos de } \\
\text { YouTube y de publicidades de la época, noticias periodísticas, } \\
\text { para luego ampliar la búsqueda de información de los niños en } \\
\text { su casa, según el tema elegido. } \\
\text { Clase 2: Confección de afiches y exposición oral de los niños } \\
\text { de la información recabada en relación al tema investigado }\end{array}$ \\
Clase 1: En forma individual y anónima realizar una narración \\
\hline GRUPO 3
\end{tabular}

\footnotetext{
${ }^{5}$ Este marco teórico se detalla con mayor amplitud en la tesis de Maestría en Didácticas Específicas (Universidad Nacional del Litoral), defendida en el año 2017 por la autora de este trabajo.
} 
El derecho como disciplina científica. Los derechos de los niños en el marco de la Educación Sexual Integral (ESI)

$7^{\circ}$ grado

\section{GRUPO 4}

¿De qué manera la biografía de Juana Azurduy puede colaborar con la comprensión de las disciplinas: Historia, Geografía, Ciencias Políticas y Sociología?

$5^{\circ}$ grado sobre situaciones escolares o familiares que hayan vivido en las que los niños han sentido que no podían hacer lo que les gusta.

Trabajo con imágenes de la vida cotidiana, y realización de preguntas orales por parte de la docente en relación con ellas: ¿Qué está bien?, ¿qué está mal?, ¿qué derechos no se cumplen en cada caso?, ¿por qué? Puesta en común y reflexión compartida entre docente - estudiantes

Clase 1: Propuesta de investigación sobre una persona anciana de la familia o del barrio. Recabar información acerca de la persona que el estudiante elija a partir de fotos antiguas, partida de nacimiento, diarios de la época, cuadernos de la escuela, entre otros.

Redactar a partir de las fuentes primarias y secundarias encontradas en una "libreta de detective" ¿qué se dice de él/ella?

Clase 2:

Trabajo en el aula con el video "La asombrosa excursión de Zamba con Juana Azurduy” (YouTube) como introducción de la problemática desde la Historia.

Ubicación en un mapa político actual de Bolivia del lugar de nacimiento, de las principales batallas en las que participó, y del fallecimiento de Juana (Geografía)

Conformación social del ejército del Alto Perú (Sociología)

Análisis de las relaciones complejas entre el Virreinato del Río de la Plata y los realistas durante las guerras por la Independencia (Ciencias Políticas)

Tabla II

Tema/problema TP № 1 (grupal) GRUPO 1

La historia como ciencia social ¿Qué es la historia como ciencia social? $3^{\circ}$ grado

\section{GRUPO 2}

La historia como disciplina científica y sus fuentes.

Diversas fuentes que utiliza el historiador para investigar la última dictadura militar en Argentina (1976-1983): publicidades, música, moda, deportes $7^{\circ}$ grado

\section{GRUPO 3}

El derecho como disciplina científica. Los derechos de los niños en el marco de la ESI

$7^{\circ}$ grado
TP № 2 Tiempo histórico (individual)

El grupo ya había incorporado el trabajo sobre la temporalidad a partir de la máquina del tiempo. Cada futura profesora, decidió elaborar materiales/recursos sobre temas históricos específicos como por ejemplo: E1: A partir de la pregunta: ¿Qué sabemos de la Casa Histórica de Tucumán?, la docente propone a los estudiantes trabajar su historia, en el marco del proceso de Independencia de nuestro país El: Pasado y presente: memoria, identidad y democracia. Historia de Abuelas de Plaza de Mayo. Derecho a la identidad. Trabajo con artículos periodísticos sobre la restitución de la nieta 125. En papeles de colores con forma de pañuelos, escribir dos palabras que se relacionen con la democracia y la identidad

Ell: Armado de un folleto educativo sobre la dictadura. Incluir en su diseño: años, conceptos, delitos de lesa humanidad, Madres de Plaza de Mayo, situación de los artistas y los músicos, mundial del '78. Diseñar un dibujo y frases significativas como "El horror de la última dictadura militar"

Elll: Línea histórica sobre el denominado "Proceso de Reorganización Nacional". Realización de preguntas que hacen referencia a los ejes del trabajo práctico № 1: ¿Por qué eran perseguidos los intelectuales, actores y músicos?

EIV: Tabla y gráfico sobre las profesiones de los desaparecidos en la última dictadura. Cuestionario con preguntas elaboradas por la docente: ¿A qué se dedicaban las personas que desaparecieron en mayor número? E1: Completar una línea temporal "Un recorrido por la Educación Sexual Integral" 1950-2017 (indicar quién gobernaba en ese momento en Argentina, los años y las Leyes nacionales sancionadas)

E2: Unir con flechas en una línea temporal "Educación sexual integral en Argentina 2006-2016", los años con la sanción de las Leyes relacionadas con ESI: ejemplo Ley de matrimonio igualitario 


\section{GRUPO 4}

¿De qué manera la biografía de Juana Azurduy puede colaborar con la comprensión de las disciplinas: Historia, Geografía, Ciencias Políticas y Sociología?

$5^{\circ}$ grado
E3: Trabajo con la Ley de identidad de género, art. 12. Crear un nuevo DNI y escribir una historia de vida, ¿por qué decidiste cambiarte el género?, ¿por qué no lo hiciste?, ¿conocés algún caso del lugar en dónde vivís? Ubicar en una línea temporal los diferentes modelos de DNI y las leyes nacionales relacionadas con la ESI, en Argentina entre 1906-2012

El: Realización de una línea temporal entre 1806-1820 en la que se destaquen los años y acontecimientos ocurridos en el Virreinato del Río de la Plata en relación a la Revolución de Mayo y a la Independencia.

Ell: Se les dará a los estudiantes de nivel primario datos desordenados temporalmente en relación con la vida de Juana Azurduy. La actividad consistirá en la realización de una línea temporal en la que incluyan: nacimiento, batallas importantes, muerte

EIII: A partir de la lectura del cuento Juana Azurduy (colección antiprincesas), y de la canción homónima de Mercedes Sosa, el futuro docente propone a los estudiantes el trabajo en grupo (4 personas).

Luego de la lectura del cuento y de escuchar la canción en clase, deberán representar corporalmente a partir de las siguientes preguntas: ¿Quién fue Juana?, ¿Cómo describe Juana al pueblo?, ¿Por qué decide pelear junto a su esposo, Manuel Padilla?

Luego de las representaciones se explicará el proceso histórico en el que Juana participó. A partir de un debate y de preguntas realizadas por el docente, también se relacionará con el presente, por ejemplo: ¿Cómo se toma la figura de la mujer en los tiempos pasados y en la actualidad? EIV: A partir de recuperar la biografía de Juana Azurduy, se les solicitará a los alumnos que traigan a la clase imágenes de mujeres de su familia, o que conozcan, trabajando.

Se fomentará un debate a partir de problemáticas actuales relacionadas con la vigencia de los estereotipos de género, en el pasado y en el presente

A continuación incluimos en detalle algunos materiales/recursos elaborados por los futuros profesores de primario, para la enseñanza del tiempo histórico, dado que consideramos que sus producciones han sobrepasado ampliamente las expectativas de la docente a cargo del taller, y de ellos mismos, en el marco de su proceso formativo:

*Trabajo práctico № 1, grupo 1:

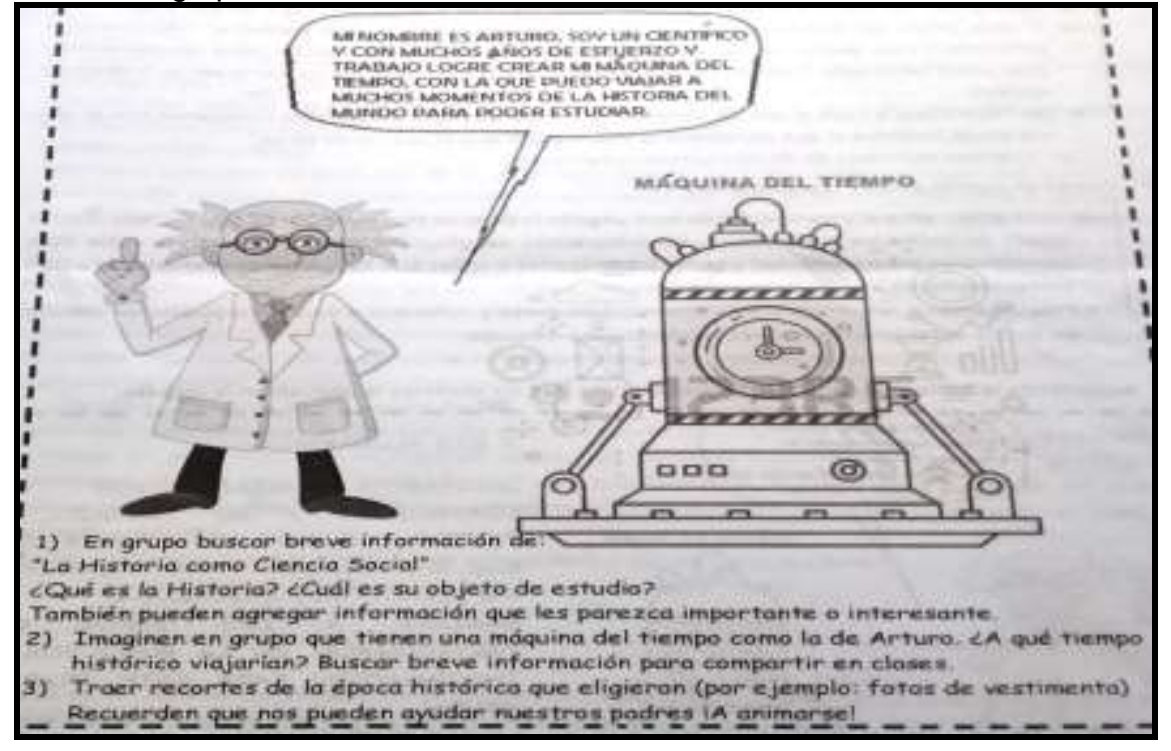

*Trabajo práctico №2, grupo 2, El: 
REVISTA DE LA Escuela de CIENCIAS DE LA EdUCACIÓN, AÑO 16, NRO. 15, VOL. 2, JULIO A DICIEMRE DE 2020. PÁGINAS 98-106. ISSN 2362-3349 (EN LÍNEA). UNA PROPUESTA DE ENSEÑANZA INNOVADORA EN LA FORMACIÓN DE PROFESORES DE NIVEL PRIMARIO: LA TEMPORALIDAD EN LA ENSEÑANZA DE LAS CIENCIAS SOCIALES. LUCRECIA MILAGROS ALVAREZ.

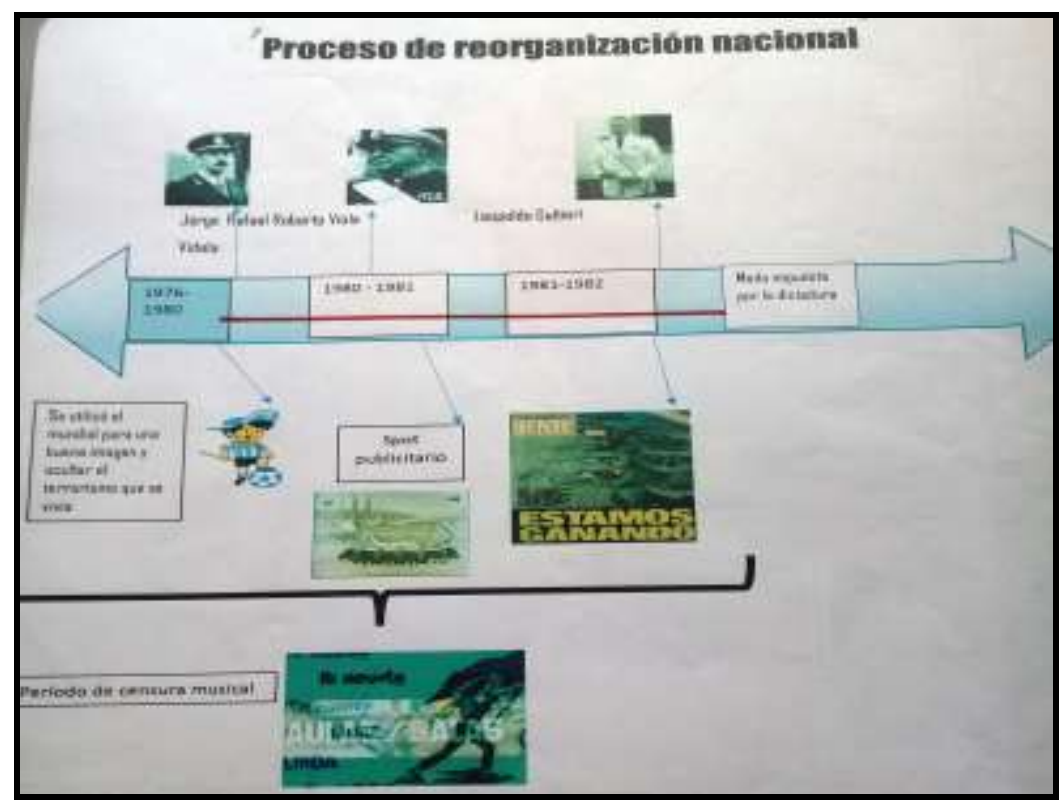

*Trabajo práctico $\mathrm{N}^{\circ}$ 2, grupo 2, Elll:

\begin{abstract}
Hace 34 ahlos que en la Argentina vivimas en democracia sin imterrupciones. La democracie se construye entre todos y todas, cotidianamente. Tenemos que cuífarla y defenderta porque dontro de la democracia se respetan muestros derechos y hay mayores grados de fuvicia $y$ libertad. Para esto es importante construir una memoria reflewiva sobre la ultims dictadura milutar. Pertsar sobre estos aspectos es daye para comprender el presente y ver qué podemo: hacer para que cada vez la sociedod sea mils justa e levalitaria.

Fuentes:
\end{abstract}

- httpa://www.educ-as/recursoa/122017/memona-verdad-v-justicia

hrtps://www abuelas org.ar/noticia-difusion/asiasay-yo-13

\title{
ACTMBas
}

Luego de leer individualmerte ef texto, trabajar en forma grupal y visualiuar las noticias del dia de aycr sobre la restitucidin de la nieta izs.

En papeittos de colores, recortar poîutuelos y escribir dos palabras que hagan referencia la democracia y a la identidad con los materiales trabajados en dase
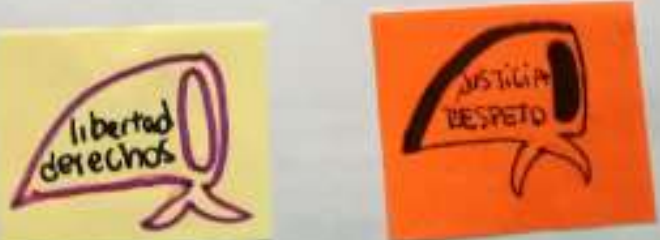

Trabajo práctico $\mathrm{N}^{\circ} 2$, grupo 3, E3: 


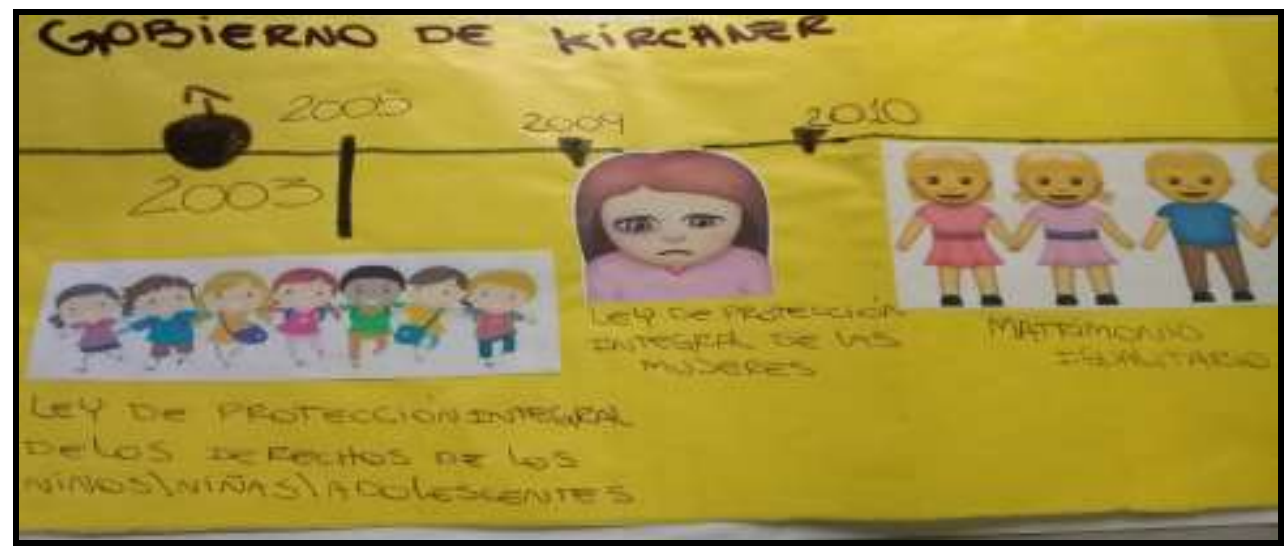

*Trabajo práctico №2, grupo 2, Ell:

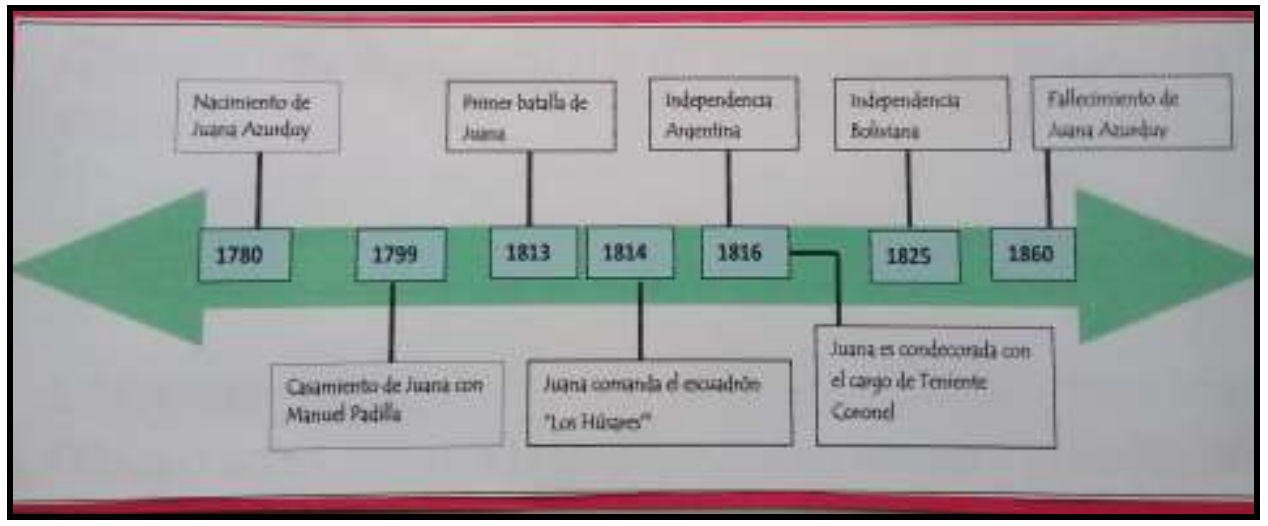

\section{Conclusiones}

Luego de la descripción y el análisis de los trabajos prácticos realizados por los futuros profesores de nivel primario en su primer año de formación, consideramos que la experiencia de enseñanza y de aprendizaje realizada en el marco del taller de Problemática de las Ciencias Sociales ha sido innovadora en todos los sentidos expresados a lo largo de este artículo.

En relación con la temporalidad, es de destacar que en los materiales/recursos múltiples y variados diseñados por los estudiantes de profesor, están presentes las categorías temporales de cambios y continuidades, y las relaciones pasado - presente.

Los estudiantes de nivel superior elaboraron/utilizaron: preguntas, artículos periodísticos de actualidad, diseño de folleto, tablas y gráficos, líneas y mapas temporales, cuentos y canciones, videos e imágenes, para incluir en las actividades para sus futuros alumnos la enseñanza del tiempo histórico.

En el marco de la realización de una primera experiencia de planificación y de diseño de materiales/recursos como docentes, consideramos que la resolución de los trabajos prácticos ha sido superadora tanto para los estudiantes, como para la docente a cargo del taller.

Como expresábamos al inicio de este artículo, es de vital importancia la escritura y divulgación de estas experiencias innovadoras en todos los niveles y modalidades del sistema educativo, dado que apuntalan la formación del profesorado y la relación entre teoría y práctica, al convertirse el aula en laboratorio privilegiado para continuar reflexionando sobre las prácticas de enseñanza y simultáneamente, como fuente para la investigación educativa.

\section{Referencias bibliográficas}

Alvarez, L. (2017). La enseñanza de las categorías temporales en relación con la Historia Reciente. Análisis de prácticas de enseñanza de estudiantes avanzados de la carrera de Profesorado de Historia, FHUCUNL. (Tesis de Maestría en Didácticas Específicas). Universidad Nacional del Litoral, Santa Fe. Recuperado de: http://bibliotecavirtual.unl.edu.ar:8080/tesis/handle/11185/931

Alvarez, L.; Andelique, M. y Coudannes M. (2016). Pensando con humor cosas terriblemente serias: los olvidados en la historia de la independencia, en M. A., Jara y C., Cerdá (comp.). La enseñanza de la Historia ante los desafíos del Bicentenario de la Independencia. Córdoba: Pueblo de la Toma Editorial, UNC, pp. 92-102. 
Benejam, P. (1999). La oportunidad de identificar conceptos clave que guíen la propuesta curricular de ciencias sociales. En: Revista ÍBER Didáctica de las Ciencias Sociales, Geografía e Historia № 21, pp. 13-22.

Benejam, P. (2013). El espacio geográfico. Ponencia presentada en las X Jornades Internacionals de Recerca. En: Didàctica de les Cienciès Socials, febrero, GREDICS-UAB, pp. 5-8.

Campilia, M. (2017). El lugar de las ciencias sociales en la enseñanza secundaria, en L. Valdemarca (coord.) Innovación educativa en la clase de historia y otras ciencias sociales. Tomo 2 Neoliberalismo y exclusiones. Trabajo, desigualdades de género y resistencias. Córdoba: UNC Editorial, pp. 11-19.

Canales, S.; Estrada, B. y Luna, S. (2006). Introducción a las ciencias sociales. México: Santillana.

Edelstein, G. (2007). Formar y formarse en la enseñanza. Buenos Aires: Paidós.

Edelstein, G. y Coria, A. (1999). Imágenes e imaginación. Iniciación a la docencia. Buenos Aires: Kapeluzs.

Imbernón, F. (2002). La investigación educativa como herramienta de formación del profesorado. Barcelona: Editorial Graó.

Jara, M. y Boixader, A. (2014). El currículo y la innovación en la enseñanza de las Ciencias Sociales, de la Geografía, de la Historia y de la educación para la ciudadanía: En: J. Pagès y A. Santisteban, Una mirada al pasado y un proyecto de futuro. Investigación e innovación en didáctica de las ciencias sociales, Vol. 1.Barcelona: AUPDCS, pp. 53-78.

Jara, M. y Funes, G. (comp.) (2016). Didáctica de las Ciencias Sociales en la Formación del Profesorado. Perspectivas y enfoques actuales. Cipoletti: UNCO.

Latorre, A. (2003). La investigación-acción. Conocer y cambiar la práctica educativa. Barcelona: Graó.

Lipsman, M. (2009). La innovación educativa, una aproximación conceptual. Recuperado de: http://www.ffyb.uba.ar/area-pedagogica-202/ampliacion-de-contenido-area-pedagogica/la-innovacioneducativa-una-aproximacion-conceptual?es

Pagès, J. (1989). Aproximación a un currículum sobre el tiempo histórico. En: Rodríguez J. (ed.): Enseñar historia. Nuevas propuestas. Barcelona: Laia/Cuadernos de Pedagogía.

Pagès, J. (1997a). El tiempo histórico. En: Benejam P. y Pagés J. (coord.) Enseñar y aprender Ciencias Sociales, Geografía e Historia en la Educación Secundaria. Barcelona: Horsori, ICE-Universidad de Barcelona.

Pagès, J. (2014). Conciencia y tiempo histórico. Revista Perspectiva Escolar-Monografías. En: Enseñanza de las Ciencias Sociales, № 1, pp. 35-40.

Pagès, J. y Santisteban, A. (1999). La enseñanza del tiempo histórico: Una propuesta para superar viejos problemas. En: Pagès J. y Santisteban A., Un currículum de Ciencias Sociales para el siglo XXI. Qué contenidos y para qué (pp. 187-207). Sevilla: Díada.

Pagès, J. y Santisteban, A. (2008). Cambios y continuidades: aprender la temporalidad histórica. En Jara, M. A (coord.). Enseñanza de la Historia. Debates y Propuestas. Neuquén: EDUCO - Editorial de la Universidad Nacional del Comahue.

Pagés, J. y Santisteban, A. (2010). La enseñanza y el aprendizaje del tiempo histórico en la educación primaria En: Cad. CEDES Campinas, vol. 30, no 82, pp. 281-309.

Pagès, J. y Santisteban, A. (2011). Enseñar y aprender el tiempo histórico. En A. Santisteban. y J. Pagés, Didáctica del Conocimiento del Medio Social y Cultural en la Educación Primaria. Ciencias Sociales para comprender, pensar y actuar (pp. 229-247). España: Síntesis.

Romero, L. A. (coord.) (2004). La Argentina en la escuela. La idea de Nación en los textos escolares. Buenos Aires: Siglo XXI.

Sanjurjo, L. (2005). La formación práctica de los docentes. Reflexión y acción en el aula. Rosario: Homo Sapiens.

Santisteban, A. (2007). Una investigación sobre cómo se aprende a enseñar el tiempo histórico. En: Enseñanza de las Ciencias Sociales, № 6, pp. 19-29.

Santisteban, A. (2014). Tiempo al tiempo en la escuela: una mirada transversal. En: Revista Perspectiva Escolar -Monografías. Enseñanza de las Ciencias Sociales, № 1, pp. 43-48.

Santisteban, A., González Monfort, N., Pagès, J. y Oller, M. (2013). La introducción de temas controvertidos en el currículo de ciencias sociales: investigación e innovación en la práctica. Ponencia presentada en el $\checkmark$ Simposio Internacional de Didáctica de las Ciencias Sociales en el ámbito Iberoamericano. Historia e identidades culturales. Barcelona.

Siede, I. (coord.) (2010). Ciencias Sociales en la escuela. Criterios y propuestas para la enseñanza. Buenos Aires: Aique.

Zenobi, V. (2016). Una geografía para comprender y explicar el mundo actual. En Revista: Quehacer educativo No 137. Junio. Revista de la Federación Uruguaya del Magisterio. Montevideo. ISSN 1510-0367, pp. 12-17.

Xiqui, J. (2016). Introducción a las ciencias sociales. México: Secretaría de Educación pública. 